\title{
OPTIMALISASI PEMBELAJARAN SEJARAH DENGAN PENERAPAN METODE ACTIVE DEBATE
}

Oleh:

Dyah Kumalasari

Abstract

This research is intended to solve the problem of optimizing the application of active debate method to improve of learning quality of History Reflection subject at the History Education Department of Social Science and Economics Faculty of the State University of Yogyakarta.

The research is designed as a classroom action research, applied to the sixth semester students, from January to July of the 2006 academic year. The research is conducted in two cycles of actions through four stages: the stage I and II encompassing the First Diagnostic and Therapy stage, and the stage III and stage IV constituting the Repeated Diagnostic and Therapy Stage. The data of study were collected by means of observations and interviews as well as evaluation of the quality of discussing skills with the grading scores of 1, 2, 3, and 4, and the data obtained were then analyzed using a $t$ test. Findings of the classroom action research through optimizing the application of the active debate method to the learning process of History Reflection subject show the significant improvement in learning process and achievement. Qualitatively, the quality of learning process increase significantly and quantitatively the learning achievement improved the averaged achievement of 2,3. Therefore, the research has been able to increase the averaged achieved score of 79,6, with a t-coefficient of 2,89344047 at the level of significance of $1 \%$ (very significant).

Keywords: Active Debate Method, Historical Learning, Learning Quality

\section{A. Pendahuluan}

Sistem pengajaran sebagai bagian integral dari sistem kegiatan pendidikan, merupakan fenomena yang harus diperbaiki dan dikembangkan oleh pihak-pihak yang terkait dan berkepentingan. Hal ini menyangkut kurikulum, metode, media pengajaran, materi pengajaran, kualitas pengajar, dan lain sebagainya sehingga tercipta sistem pengajaran yang baik dan berorientasi ke masa depan. Dengan demikian perlu dikembangkan prinsipprinsip belajar yang berorientasi pada masa depan, dan menjadikan peserta didik tidak hanya sebagai objek belajar tetapi juga subjek dalam belajar. Pendidikan tidak lagi berpusat pada lembaga atau pengajar, yang hanya akan 
mencetak para lulusan yang kurang berkualitas, melainkan harus berpusat pada peserta didik sebagai pusat belajar, yang tidak hanya "disuapi" dengan materi tetapi juga harus diberi kesempatan untuk bersikap kreatif dan mengembangkan diri sesuai dengan potensi intelektual yang dimilikinya.

Mengajar merupakan suatu aktivitas profesional yang memerlukan ketrampilan tingkat tinggi dan mencakup hal-hal yang berkaitan dengan pengambilan keputusan-keputusan ${ }^{1}$ Sekarang ini pengajar lebih dituntut untuk berfungsi sebagai pengelola proses belajar mengajar yang melaksanakan tugas yaitu dalam merencanakan, mengatur, mengarahkan, dan mengevaluasi. Keberhasilan dalam belajar mengajar sangat tergantung pada kemampuan pengajar dalam merencanakan, yang mencakup anatra lain menentukan tujuan belajar peserta didik, bagaimana caranya agar peserta didik mencapai tujuan tersebut, sarana yang diperlukan, dan lain sebagainya.

Dalam proses belajar mengajar, pengajar perlu mengadakan keputusankeputusan, misalnya metode apakah yang perlu dipakai untuk mengajar mata pelajaran tertentu, alat dan media apakah yang diperlukan untuk membantu peserta didik membuat suatu catatan, melkukan praktikum, menyusun makalah diskusi, atau cukup hanya dengan mendengar ceramah pengajar saja. Dalam proses belajar mengajar pengajar selalu dihadapkan pada bagaimana melakukannya, dan mengapa hal tersebut perlu dilakukan. Begitu juga dalam hal evaluasi atau penilaian yang digunakan, bagaimana kriterianya, dan bagaimana pula kondisi peserta didik sebagai subjek belajar yang memerlukan nilai itu.

Dalam rangka pengembangan pengajaran sejarah agar lebih fungsional dan terintegrasi dengan berbagai bidang keilmuan lainnya, maka terdapat berbagai bidang yang seyogianya mendapat perhatian, yaitu: pertama, untuk menjawab tantangan masa depan, kreativitas dan daya inovatif diperlukan agar bangsa Indonesia buka sekedar menjadi konsumen IPTEK, konsumen budaya, maupun penerima nilai-nilai dari luasr secara pasif, melainkan memiliki keunggulan komparatif dalam hal penguasaan IPTEK. Oleh karena itu, kreativitas perlu dikembangkan melalui penciptaan situasi proses belajar mengajar yang kondusif, di mana pengajar mendorong vitalitas dan kreativitas peserta didik untuk mengembangkan diri. Peserta didik perlu diberi kesempatan untuk belajar dengan daya intelektualnya sendiri, melalui proses

${ }^{1}$ Winata Putera, US. (1992). Model-Model Pembelajaran. Jakarta: Depdikbud. Hlm. 86. 
rangsangan-rangsangan baik yang berupa pertanyaan-pertanyaan maupun penugasan, sehingga peserta didik dapat melihat suatu hal dari berbagai sudut pandang dan dapat menemukan berbagai alternative pemecahan masalah yang dihadapi.

Peserta didik dapat mengembangkan daya kreativitasnya apabila proses belajar mengajar dilaksanakan secara terencana untuk meningkatkan dan membangkitkan upaya untuk kompetitif. Oleh karena itu, proses belajar mengajar yang memberi peluang kepada peserta didik untuk menyelesaikan tugas secara kompetitif perlu disosialisasikan, kemudian juga perlu adanya penghargaan yang layak kepada mereka yang berprestasi. Hal ini akan berdampak positif terhadap terbentuknya rasa percaya diri pada peserta didik. Pengalaman ini selanjutnya dapat menjaga proses pembentukan kemandirian. Dalam hal ini peserta didik juga perlu dilibatkan dalam proses belajar mengajar yang memberikan pengalaman bagaimana peserta didik bekerja sama dengan peserta didik yang lain seperti dalam hal berdiskusi. Pengalaman seperti ini selanjutnya akan dapat membentuk sikap kooperatif dan ketahanan bersaing dengan pengalaman nyata untuk dapat menghargai segala kelebihan dan kelemahan masing-masing.

Dalam rangka optimalisasi pembelajaran sejarah khususnya untuk mata kuliah Refleksi Sejarah, maka dirasakan perlu untuk mengadakan penelitian tindakan kelas mengenai "Penerapan Metode Active debate dalam Pembelajaran Mata Kuliah Refleksi Sejarah di Jurusan Pendidikan Sejarah FISE UNY", sebagai bagian dari proses pendidikan. Dengan penerapan metode active debate secara optimal diharapkan mahasiswa akan lebih aktif dan kreatif dalam mencari sumber-sumber atau referensi. Dengan aktif dan kreatifnya baik dalam mencari sumber-sumber maupun dalam diskusi sebagai upaya pemecahan masalah, mahasiswa benar-benar akan memahami materi perkuliahan. Dengan dikuasainya materi perkuliahan, dimungkinkan mereka akan mendapatkan nilai yang optimal dan pada gilirannya indeks prestasinya akan meningkat. Dengan demikian Jurusan Pendidikan Sejarah akan menghasilkan lulusan yang berkualitas dan nantinya akan menjadi guru-guru sejarah yang profesional.

\section{B. Cara Penelitian}

Penelitian ini adalah penelitian tindakan kelas yang dilaksanakan pada mahasiswa semester VI Jurusan Pendidikan Sejarah FISE UNY. Tindakan yang dilakukan merupakan upaya meningkatkan kualitas pembelajaran mahasiswa 
dalam mencari, menemukan, dan memecahkan permasalahan dalam perkualiahan dengan penerapan metode active debate, yang pada dasarnya juga merupakan penerapan metode sejarah, yaitu: heuristic, kritik, interpretasi, dan historiografi.

Pelaksanaan penelitian ini dilakukan dalam dua siklus, yakni siklus pertama sebagai imolementasi tindakan, sedangkan siklus kedua sebagai perbaikan. Alur kegiatan pada siklus I adalah sebagai berikut: tahap I, tahap ini meliputi kegiatan pengumpulan data tentang pembelajaran sejarah, yang meliputi identifikasi masalah, perumusan masalah, analisis masalah, dan perumusan hipotesis tindakan. Pada tahap ini sumber data diperoleh dari ketua Jurusan, pimpinan program studi, dosen, dan referensi.

Tahap II adalah tahap terapi, meliputi kegiatan perencanaan tindakan, pelaksanaan, pemantauan, dan perbaikan tindakan. Pada tahap ini melibatkan peran aktif dan intensif secara bersama-sama antara dosen, peneliti, dan pakar pendidikan sejarah. Alur kegiatannya adalah sebagai berikut: (1) kelas dibagi menjadi 2 atau 3 kelompok, dosen memberi informasi singkat tentang materi dan tugas yang harus dikerjakan oleh masing-masing kelompok dengan merumuskan masalahnya; (2) masing-masing kelompok/individu diberi waktu kurang lebih 30 menit untuk mencari sumber-sumber yang berkaitan dengan permasalahannya, dapat berupa narasumber, buku, majalah, jurnal, dan lain sebagainya; (3) setelah sumber terkumpul dilaksanakan diskusi untuk membuktikan hipotesis yang dibuat, juga diberikan penilaian/skor: 1, 2, 3, atau 4 tergantung dari keaktifan berdiskusi, kualitas jawaban atau sanggahan, dan lain sebagainya. Ketiga alur tersebut juga dilaksanakan pada siklus 2.

Tahap III adalah tahap diagnostik ulang. Pada tahap ini meliputi kegiatan mengevaluasi hasil tindakan yang sudah dilakukan, melakukan verifikasi hipotesis tindakan, spesifikasi permasalahan yang belum teratasi serta mengambil kesimpulan penyebabnya (khusus untuk masalah yang belum teratasi) berdasarkan diagnostik ulang tersebut.

Tahap IV adalah tahap terapi ulang. Pada tahap ini meliputi kegiatan perencanaan tindakan perbaikan ulang (untuk permasalahan yang belum teratsai), pelaksanaan, dan pemantauan. Pihak-pihak yang berperan dalam kegiatan ini adalah pimpinan jurusan, pimpinan program studi, dosen, dan peneliti.

\section{Hasil Penelitian dan Pembahasan}


Dari tahap I: tahap Diagnostik dan Tahap II: Tahap Terapi menghasilkan nilai/skor seperti dalam Tabel I sebagai berikut:

Tabel I

Nilai/Skor Tahap I dan Tahap II: Diagnostik dan Terapi (XI)

$(\mathrm{N}: 60)$

\begin{tabular}{|l|c|}
\hline Ubahan & Besarnya Nilai \\
\hline Nilai/Skor Tertinggi & 90 \\
Nilai/Skor Terendah & 66 \\
Rentang Nilai/Skor & 24 \\
Rerata & 77.3 \\
Simpang Baku & 7.4 \\
N & 60 \\
\hline
\end{tabular}

Melihat rentang nilai/skor X1 (24) dan simpang baku X1 (7.4) memberikan diagnostik bahwa nilai/skor X1 belumlah begitu homogen. Untuk memperbaiki nilai/skor para peserta dilakukan Tahap III dan Tahap IV: Tahap Diagnostik dan Tahap Terapi Ulang. Pada Tahap III dilakukan evaluasi hasil tindakan yang telah dilakukan, verifikasi hipotesis tindakan, spesifikasi permasalahan yang belum teratasi, serta berdasarkan diagnostik ulang menarik kesimpulan tentang sebab-sebabnya terutama belum teratasinya permasalahan.

Pada tahap IV, Tahap Terapi Ulang, dilakukan perencanaan perbaikan ulang untuk kemudian dilaksanakan dengan tiap-tiap kali memantaunya. Hasil nilai/skor pada Tahap III dan Tahap IV menunjukkan hasil yang lebih baik dan lebih homogen. Keadaan nilai/skornya nampak dalam Tabel 2 berikut ini

\section{Tabel 2}

Nilai/Skor Tahap III dan Tahap IV: Diagnostik dan Terapi Ulang (X2)

\begin{tabular}{|l|c|}
\hline Ubahan Skor & Besarnya Nilai \\
\hline Nilai/Skor Tertinggi & 90 \\
Nilai/Skor terendah & 67 \\
Rentang Nilai/Skor & 23 \\
Rerata & 79.6 \\
Simpang Baku & 5.1 \\
N & 60 \\
\hline
\end{tabular}


Dibandingkan dengan rentang nilai/skor X1 (24) dan simpang baku nilai/skor X2 (23) dan simpang baku X2 (5.1), menunjukkan bahwa nilai/skor Tahap III dan Tahap IV: Diagnostik dan Terapi Ulang (X2) berhasil dengan baik, sebab dengan nyata kenaikan rerata X2 (79.6) sebesar 2.3 dibandingkan dengan rerata X1 (77.4).

Setelah hasil komputasi Tahap III dan Tahap IV sebagai Diagnostik dan Terapi Ulang terhadap Tahap I dan Tahap II penerapan metode active debate pada pembelajaran mata kuliah Refleksi Sejarah menunjukkan kenaikan ratarata nilai/skor sebesar 2.3 (dari 77.3 menjadi 79.6), maka langkah selanjutnya adalah untuk membuktikan apakah kenaikan rerata sebesar 2.3 itu signifikan atau tidak. Untuk itu perlu dilakukan komputasi dengan menggunakan rumus uji-t $(t-T e s t)$ :

$$
t=\frac{\sum \mathrm{D}}{\frac{\sqrt{\mathrm{N} \sum \mathrm{D}_{2}-\left(\sum \mathrm{D}\right)^{2}}}{\mathrm{~N}-1}}
$$

Keterangan: $\mathrm{t} \quad$ Koefisien $\mathrm{t} \mathrm{D}$

: beda X2 - X1

$\sum \mathrm{D} \quad$ : sigma (jumlah) beda $\mathrm{X} 2-\mathrm{X} 1$

$\sum \mathrm{D}_{2} \quad$ : sigma (jumlah) kuadrat beda $\mathrm{X} 2-\mathrm{X} 1$

$\mathrm{N} \quad$ : jumlah individu mahasiswa

Hasil komputasi dari $\mathrm{N} ; \sum \mathrm{D} ; \sum \mathrm{D}_{2}$; dan $\mathrm{N}-1$ adalah sebagai berikut:

$\begin{array}{ll}\mathrm{N} & 60 \\ \sum \mathrm{D} & 109 \\ \sum \mathrm{D}_{2} & : 1593,5 \\ \mathrm{~N}-1 & 59\end{array}$

Jika angka hasil komputasi tersebut dimasukkan ke dalam rumus Uji-t tersebut, maka diperoleh hasil sebagai berikut:

$\mathrm{t}=\frac{109}{\sqrt{\frac{60 \times 1593.5-11881}{1}}}=2.89344047$


Ternyata hasil komputasi koefisien $\mathrm{t}=2.89344047$ ini memiliki makna sangat signifikan, karena harga $\mathrm{t}=2.89344047$ lebih besar terhadap harga kritis $\quad \mathrm{t}=$ 2.660 pada taraf signifikansi $1 \%$.

Dari hasil penelitian tersebut dapat disimpulkan bahwa penerapan metode active debate telah mampu meningkatkan proses pembelajaran. Indikator meningkatnya proses pembelajaran melalui penerapan metode active debate dapat dilihat dari aktivitas mereka baik pada Tahap I dan Tahap II: Tahap Diagnostik dan TAhap Terapi dan pada Tahap III dan Tahap IV: Tahap Diagnostik dan Terapi Ulang. Melalui tahap-tahap tersebut mahasiswa tidak dapat tidak harus aktif untuk: (1) membuat perencanaan dalam pemecahan masalah; (2) merumuskan proposisi-proposisi yang jelas, menyeluruh, tepat, dan teruji dengan bukti dan argumentasi; (3) mengkomunikasikan pemikirannya dengan lugas dan tegas; (4) harus setiap kali mampu mengubah statusquo melemahkan posisinya untuk dapat bertahan dalam kualitasnya. Ini semua jelas akan memacu pendalaman dalam pemahaman dan penguasaan materi dan bahan pengetahuan yang diperlukan, yang jelas meningkatkan dalam melakukan diskusi para mahasiswa. Indokator-indikator tersebut jelas secara kualitatif membenarkan hipotesis pertama, bahwa penerapan metode active debate mampu meningkatkan kualitas proses pembelajaran.

Secara kuantitatifhipotesis kedua yang menyatakan bahwa penerapan metode active debate dapat meningkatkan kualitas hasil pembelajaran Refleksi Sejarah dapat dibenarkan dan dapat diterima. Melalui proses diagnostik dan Terapi Ulang rerata prestasi pembelajaran Refleksi Sejarah dapat ditingkatkan sebesar 2.3 dari yang semula 77.3 menjadi 79.6. Uji - t menunjukkan bahwa kenaikan rerata sebesar 2.3 tersebut sangat signifikan. Koefisien $t=2.893443047$ jauh melebihi harga kritis koefisien $t$ pada taraf signifikansi $1 \%$ yang besarnya 2.660. Demikianlah penerapan metode active debate pada mata kuliah Refleksi Sejarah mampu meningkatkan kualitas proses pembelajaran sejarah, dan karenanya hasil prestasi pembelajaran Refleksi Sejarah dapat ditingkatkan pula secara signifikan baik secar kualitatif maupun kuantitatif.

\section{Kesimpulan}

Hasil penelitian penerapan metode active debate pada mata kuliah Refleksi Sejarah telah berhasil menunjukkan bagaimana mengoptimalkan metode active debate guna meningkatkan kualitas pembelajaran dan hasil prestasi 
pembelajaran mata kuiah Refleksi Sejarah pada Jurusan Pendidikan Sejarah FISE UNY.

Penerapan metode active debate dalam dua siklus, ialah Tahap I dan II: Tahap Diagnostik dan Terapi, dan Tahap III dan IV: Tahap Diagnostik dan Terapi Ulang mampu mengoptimalkan proses pembelajaran sejarah: (1) mahasiswa aktif mencari, menemukan, dan memecahkan permasalahan pembelajaran sejarah; (2) memberi motivasi kepada mahasiswa untuk secara aktif dan kreatif dalam berpartisipasi dalam pembelajaran; (3) juga meningkatkan motivasi dan kemampuan para dosen dalam evaluasi proses pembelajaran dan hasil pembelajaran secara berkelanjutan dalam upaya memperbaiki dan mengembangkan proses pembelajaran sejarah. Proses tersebut ternyata mampu meningkatkan kualitas proses pembelajarannya dan kualitas hasil prestasi pembelajarannya.

Hasil prestasi pembelajaran dalam dua siklus penerapan metode active debate secara signifikan mampu meningkatkan rerata prestasi pembelajaran dari 77.3 menjadi 79.6 atau sebesar 2.3 dengan koefisien $t$ sebesar 2.89344047 pada taraf signifikansi $1 \%$.

\section{E. Saran-Saran}

Keberhasilan peningkatan kualitas proses pembelajaran dan hasil prestasi pembelajaran sejarah secara signifikan melalui penerapan metode active debate secara implicit sekaligus mengandung saran-saran:

1. Diterapkannya metode active debate pada mata kuliah-mata kuliah lain pada Jurusan Pendidikan Sejarah, sehingga hasilnya akan semakin memantapkan signifikansi metode active debate sebagai metode pembelajaran sejarah;

2. diterapkannya juga metode-metode pembelajaran sejarah lainnya bersifat student centered oriented pada berbagai mata kuliah sejarah dengan harapan akan semakin meningkatkan motivasi pembalajaran mahasiswa;

3. Lembaga pendidikan, khususnya Jurusan Pendidikan Sejarah, FISE UNY perlu menanggapi secara positif terhadap hasil penemuan ini dengan meningkatkan perhatian dan partisipasi para tenaga pengajar. Penerapan metode-metode pembelajaran yang bersifat student centered oriented jelas menuntut aktivitas dan kreativitas dosen baik dalam pembelajarannya maupun dalam teknik evaluasi hasil pembelajarannya. 


\section{Daftar Pustaka}

A. Syafii Maarif. (1995). Historiografi dan Pengajaran Sejarah. Yogyakarta: FPIPS IKIP Yogyakarta.

Banathy, Bela H. (1992) A Sistems View of Education: Concepts and Principles for Effective Practice. Englewood Cliffs: Educational Technology Publications.

Hariyono. (1992). "Pengajaran Sejarah dan Egenwelt Subjek-Didik". Historika. No. 1 Vol 1. Surakarta: PPs Pendidikan Sejarah IKIP Jakarta KPK UNS.

MD. Dahlan. (1999). Model-Model Mengajar. Bandung: Diponegoro.

Moedjanto, G. (1999). “Reformasi Pengajaran Sejarah Nasional”. Kompas. 1 Mei 1999.

Soewarso. (2000). Cara-Cara Penyampaian Pendidikan Pendidikan Sejarah Untuk Membangkitkan Minat Peserta Didik Mempelajari Sejarah Bangsanya. Jakarta: Dirjendikti Depdiknas.

Winata Putera, US. (1992). Model-Model Pembelajaran. Jakarta: Depdikbud.

\section{BIODATA PENULIS}

Dyah Kumalasari, Lahir di Klaten, 18 Juni 1977. Lulus dari Fakultas Sastra Universitas Sebelas Maret Surakarta spesialisasi Ilmu Sejarah, tahun 2000. S2 ditempuh di Program Pascasarjana UNS di Jurusan Pendidikan Sejarah, lulus tahun 2003. mengabdi di UNY sejak akhir tahun 2003 di Jurusan Pendidikan Sejarah FISE UNY, dengan spesialisasi mata kuliah pada Sejarah Pendidikan dan Sejarah Indonesia Masa Pergerakan Nasional. Karya ilmiah yang pernah dibuat di antaranya adalah: Point dan Coins, Studi pembelajaran bermakna dalam Mata Kuliah Dasar-Dasar Ilmu Sejarah (2004); Hambatan Mahasiswa Program Studi Ilmu Sejarah dalam Penyusunan Tugas Akhir (2005); Optimalisasi Pembelajaran Sejarah Dengan Penerapan Metode Active Debate (2005). 